\title{
La tolérance polonaise à travers le prisme de l'intolérance française au XVI ${ }^{\mathrm{e}}$ siècle
}

JEAN-MARIE

LE GALL

Summary: This article analyses the reception in France of the Warsaw Confederation (1573) which established religious tolerance in Poland as Henry of Valois ascended the throne, leaving behind the Kingdom of France rent by civil war. In France, some contemporary accounts prefer not to mention such tolerance and cast a veil of silence over confessional diversity in this part of Christendom. Other writers, equally Catholic but more intransigent, assert that this tolerance is illegal, effectively constituting an oath against the king. Protestants, for their part, are unwilling to promote this model of religious peace, which they do not seek, favouring negotiations between the Valois and the Polish Diet to obtain concessions for French Protestants. Finally, for the crown, what is key in Poland is not so much religious tolerance as the goodwill of the nobility and fidelity to the king.

$Z^{\mathrm{n}}$ janvier 1573, l'assemblée chargée d'élire le futur roi de Pologne futur souverain devra s'engager à respecter; parmi celles-ci, l'obligation de maintenir la paix religieuse que catholiques et protestants polonais se sont mutuellement promis de garantir.

Cette confédération de Varsovie est une des nombreuses paix de religion élaborées au XVIe siècle. Mais, de l'avis de Maciej Serwanski, elle n' a guère retenu l'attention des historiens ${ }^{1}$. Peut-être parce qu'elle ne cadre pas avec le canon européen de la paix religieuse qu'a pu ainsi dégager Olivier Christin d'une analyse comparée des paix française, suisse et allemande. Paix préventive, elle ne résulte pas d'une guerre intestine. Elle ne suit pas non plus le temps des bûchers et des martyrs ${ }^{2}$. Elle est le fait des nobles plus que des villes qui prêtent un serment du reste assez 
comparable à ceux qu' Olivier Christin a repérés dans une dizaine de petites ou moyennes villes du sud-est de la France. Elle est inspirée par un humanisme - chrétien ou civique - qui ici ne défaille pas. Sans tout tolérer, elle accepte une plus grande liberté de culte que les paix de religion de l'Europe occidentale, étroitement bi-confessionnelles. Surtout, elle n'est pas une concession régalienne mais un engagement adopté durant un interrègne par la diète de convocation et incorporée non sans mal dans les nouvelles lois fondamentales établies par la diète d'élection qui porte son choix sur Henri d'Anjou, frère de Charles IX ${ }^{3}$.

La montée sur le trône des Jagellon d'un Valois suscite l'intérêt des Français de l'époque pour ce lointain pays et vice versa ${ }^{4}$. La confédération de Varsovie a été suscitée en partie par la nouvelle de la récente Saint-Barthélemy. Avant d'élire le frère du roi qui légitima le massacre, les Polonais voulaient empêcher la répétition dans leur pays d'une telle violence ${ }^{5}$. Mais si l'écho de la Saint-Barthélemy en Pologne a été analysé, il n'existe aucune étude de la présentation qui a été faite en France de la tolérance expérimentée par les Polonais. A-t-elle servi de modèle pour résorber les guerres de religion qui divisent plus que jamais le royaume au milieu des années 1570? Et plus tard, l'édit de Nantes est-il une confédération française, comme diront les Polonais 6 ? La tentation est grande d'apprécier l'altérité à l'aune de l'identité et l'inconnu à la mesure du connu.

Il existe trois approches possibles des paix de religion. Une première consiste à analyser l'élaboration de chaque paix dans son contexte spécifique $^{7}$. Une autre méthode privilégie la démarche comparative. Fort en vogue, celle-ci nécessite cependant d'être maniée avec prudence, car la comparaison est souvent, selon l'expression de Michel Espagne, « le recours à un ethnocentrisme historiographique ${ }^{8}$. Le comparatisme nourrit une réflexion identitaire. L'autre est par rapport à soi un moyen de se valoriser, de se dénigrer sans jamais se quitter. En outre, la démarche comparative porte en elle une conception mécanique et abstraite du temps qui fait de la simultanéité un facteur d'explication causale, en négligeant la perception sociale d'un évènement ${ }^{9}$.

Si la démarche comparative a le mérite de décloisonner les historiographies, elle ne doit pas nous conduire à recomposer le passé sur notre présent, à confondre l'Europe d'hier avec notre actuelle communauté européenne, dans une perspective d'efficience civique. Les paix de religion ont une inscription territoriale et procèdent d'une histoire spécifique qui rend parfois hasardeuse la comparaison terme à terme. Peut-on mettre sur le même plan la situation polonaise nourrie d'une longue tradition de pluralisme ethnique et religieux avec la France qui découvre au XVIe siècle 
la fracture religieuse et ses divisions sociale, familiale, politique et nationale?

Pour échapper à cette histoire comparative autocentrée et finaliste, fondée sur des bilans que l'on arrête à la date qui arrange le projet démonstratif, il est possible de recourir à la théorie des transferts culturels. Échappant à l'histoire généalogique des anticipations, cette approche replace les paix de religion dans des relations dynamiques, de circulation, d'influence et de réception. Attentifs à l'écho que la Saint-Barthélemy avait pu rencontrer dans l'élaboration de la tolérance polonaise, les historiens ont jusqu'alors délaissé l'analyse de la réception de la confédération de Varsovie dans la France de Charles IX, en proie à une douloureuse guerre civile ${ }^{10}$. Or, l'élection d'Henri d'Anjou procure au royaume de France une multitude d'informations sur la Pologne, fournies par les diplomates ${ }^{11}$, et y suscite une curiosité que s'efforcent de satisfaire des publications en langue vulgaire décrivant soit directement la Pologne, soit les rituels d'informations comme les harangues de bienvenues ou les cérémonies organisées en France et en Pologne pour l'avènement du nouveau monarque. Sans négliger les manuscrits qui dévoilent ce que les milieux dirigeants savent et pensent, notre étude se focalisera surtout sur les imprimés qui permettent d'apprécier ce que l'on présentait de la situation religieuse polonaise au plus grand nombre. Comment percevaiton la paix de religion polonaise dans une France au paroxysme de l'intolérance religieuse?

\section{Une Pologne sans problème}

La Pologne est composée de Polonais, de Ruthènes et de Lituaniens, chacun ayant leur langue. Cette diversité ethnique fait que l'unité religieuse n'a jamais existé. Au début du siècle, il y a deux millions d'orthodoxes ayant les mêmes droits politiques que les trois millions de catholiques ${ }^{12}$. De plus, la Pologne est une frontière de chrétienté, et pas seulement de catholicité. Le Turc n'est pas loin, les Tatares menacent sans cesse, des formes de paganisme subsistent et les communautés juives sont importantes.

$\mathrm{Au} \mathrm{XVIe} \mathrm{siècle,} \mathrm{la} \mathrm{fracture} \mathrm{de} \mathrm{l'église} \mathrm{latine} \mathrm{s'opère} \mathrm{très} \mathrm{tôt} \mathrm{en}$ Pologne. Le passage au luthéranisme de l'ennemi héréditaire, l'ordre teutonique, s'effectue avec le consentement du roi de Pologne moyennant l'hommage du duc au souverain polonais. C'est « le premier acte conclu en Europe entre un prince protestant et un souverain catholique ${ }^{13}$. Le luthéranisme se développe dans la bourgeoisie allemande, sans pouvoir s'imposer dans les campagnes, restées catholiques, ni sur la noblesse qui ne rejoint massivement le camp de la réforme d'inspiration calviniste que 
vers 1550 . Mais à cette date, on assiste aussi à une scissiparité du mouvement réformé, avec l'essor des antitrinitaires, appelés sociniens ou ariens. Face à ce débordement, les frères bohèmes, les calvinistes et les luthériens s'entendent au consensus de Sandomir de 1570, pour se reconnaître mutuellement la liberté de croyance et de culte, mais en la déniant aux sectes. Les progrès du protestantisme ne s'opèrent d'ailleurs pas seulement au détriment des catholiques mais aussi des orthodoxes ${ }^{14}$.

Or les Français d'alors connaissent mal cette complexité religieuse et la production imprimée ne les éclaire guère. Avant l'élection d'Henri de Valois, les ouvrages en français présentant le pays sont rares et laconiques.

Celui du cardinal polonais Hosius, Des sectes et hérésies de nostre temps traduit par Jean de Billy et publié à plusieurs reprises depuis 1561, n'évoque pas vraiment la diversité confessionnelle polonaise tout simplement parce que l'hérésie, schismatique et satanique, lui paraît être un produit d'importation, fabriqué en Allemagne ou en Suisse. L'hérétique et l'hérésie sont étrangers à la Pologne ${ }^{15}$. Il dénonce les sectes en général mais ne veut pas dénigrer son pays.

On répète souvent que la Polonia de Martin Cromer est l'ouvrage par lequel les contemporains connaissent la Pologne du XVIe siècle. Mais il n'est publié qu'en 1578, au moment où l'intérêt des français pour ce royaume lointain est retombé. De plus, il n'a jamais été édité en France, et encore moins traduit ${ }^{16}$. Pour connaître la Pologne, il faut avoir recours à Sébastien Munster qui sera expurgé et traduit en français par Belleforest en 1575. Mais l'histoire polonaise s'y trouve figée sur la situation de 1550 largement dépassée en 157017. En outre, Munster et Belleforest font une histoire des règnes et des vicissitudes du royaume, sans décrire sa situation religieuse.

L'élection d'Henri d'Anjou sur le trône des Jagellon provoque une certaine curiosité pour la Pologne dont témoigne la publication à Paris mais aussi à Rouen d'ouvrages en français décrivant le lointain royaume. Mais ces nouvelles livraisons sont loin d'informer les Français sur la situation confessionnelle. Souvent dédiés au futur Henri III, ils évoquent plus le nouveau et les anciens rois que le royaume polonais. Ainsi La Pologne, parue en 1573, ouvrage d' un jeune étudiant du collège de Navarre, François d'Amboise (1550-1619), qui a accompagné Monluc en Pologne en août 1572, n'est qu'un recueil d'éloges du nouveau souverain, disculpé de la Saint-Barthélemy et loué pour sa vaillance. Cet opuscule ancré dans la littérature encomiastique ne dit rien de la situation religieuse polonaise ${ }^{18}$.

Ancien secrétaire de François de Clèves, duc de Nevers, devenu secrétaire du roi vers $1565^{19}$, Blaise de Vigenère publie en 1573 un in quarto de 114 pages intitulé La description du royaume de Pologne avec 
les statuts, constitutions et mœurs... . Dans cet ouvrage dont il est difficile de cerner les sources, la situation religieuse décrite est là encore largement figée ou édulcorée ${ }^{20}$. La Pologne est certes encombrée de païens, de Tatares, de musulmans, d'orthodoxes, de Russes ou de Valaques. Il souligne le respect des musulmans pour la Vierge, comme pour mieux suggérer l'isolement des protestants. Il développe de larges considérations sur les orthodoxes, qui communient sous les deux espèces et dont les prêtres se marient, comme pour mieux suggérer la viabilité des solutions de concorde autour de ces concessions. Mais il note aussi que les orthodoxes ignorent le Purgatoire et haïssent les Juifs ${ }^{21}$. Le pouvoir des évêques dans le royaume de Pologne est largement décrit, sans qu'il soit fait allusion au mouvement d'exécution des lois qui veut le réduire ${ }^{22}$. Ces prélats ont « la cognoissance des différens de la religion, hérésies, schismes, blasphèmes apostasies, sacrilèges, magie » et « les capitaines sont tenus de faire exécuter les sentences d'excommunication ${ }^{23}$. Mais l'ouvrage ne dit rien de ces hérésies et masque que Sigismond Auguste a en 1562 interdit au bras séculier, aux starostes, d'exécuter les sentences ecclésiastiques ${ }^{24}$. Ce royaume sans hérésie, mais multireligieux est toutefois tenu pour « vray et unique rempart » contre le Turc, le Moscovite, le Russe et le Tatare ${ }^{25}$. Telle est la Pologne, arrangée, imaginée et présentée par Blaise de Vigenère. Il y tait les dissensions religieuses entre chrétiens.

À ce silence des ouvrages de géographie répond celui des rares voyageurs français en Pologne ayant légué leurs impressions ou des relations, imprimées bien plus tard. Le poète Philippe Desportes a accompagné Henri de Valois dans son nouveau royaume. Il en conserve un effroyable souvenir, mais aucune impression religieuse ${ }^{26}$. Le catholique François de Pavie, baron de Fourquevaux, passe deux semaines en Pologne en 1585; il nous parle des auberges, des villes, des mines et des nobles, mais rien sur la pratique religieuse, sinon pour constater la curieuse manière qu'ont les femmes de battre leur coulpe à l'élévation ${ }^{27}$. Douze ans plus tard, le très prolixe Rochelais protestant Jacques Esprinchard n'est attentif qu'à la vitalité des jésuites et à la situation des juifs, nombreux « à cause qu'il n'i a point lieu en toute chrestienté où ils ayent de si beaux privilèges qu'en Poloigne ${ }^{28}$. Esprinchard nous parle de tout, sauf de la cohabitation confessionnelle. C'est aussi l'attitude d'un Montaigne, dont les Essais n'évoquent jamais la situation confessionnelle polonaise.

Or Montaigne, comme Vigenère, comme François Beauduin ont lu et se sont inspirés d'un ouvrage paru à Bâle en 1571, la Chronica sive historia polonicae compendiosa de Jan Herburt de Fulstin, castellan de Sanoc, l'un des membres de l'ambassade polonaise en France, que Beauduin a connu dans ses tractations quotidiennes avec les ambassadeurs polonais. Or, ce 
texte, un abrégé du De origine et rebus gestis polonorum de Martin Cromer paru à Bâle en 1558, est avant tout une chronique des rois.

En fait, plus que le royaume, ce sont les monarques polonais qui intéressent. Herburt de Fulstin a écrit son ouvrage pour faire connaître la Pologne aux étrangers et son texte est donc «épuré d'évènements négatifs ${ }^{29}$. Les Chroniques et anales de Poloigne de Hebertus de Fulstin ont été traduites et publiées par François Beauduin (Histoire des roys et princes de Pologne, Paris, 1573) et par Blaise de Vigenère, qui les dédie à Henri de Valois. Blaise de Vigenère énumère sur 487 pages les rois successifs jusqu'à Henri Ier, 43e successeur d'une série qui compte « 15 non illuminés de la grâce », c'est-à-dire non chrétiens et « 27 très chrétiens et catholiques » selon le comput établi dans la lettre dédicatoire. Chez Vigenère comme chez Beauduin, Sigismond est le modèle royal par excellence, loué pour son caractère pacifique, refusant la croisade, mais fort dévot et catholique comme l'atteste l'énumération de ses fondations pieuses ${ }^{30}$. Si, fidèle à la version d'Herburt de Fulstin, Beauduin ignore le successeur de Sigismond, Blaise de Vigenère consacre à Sigismond-Auguste dont hérite Henri de Valois un portrait peu flatteur, celui d'un oisif voluptueux ${ }^{31}$. Sans rien dévoiler de sa politique religieuse, faite de tolérance envers les protestants et de réception des articles du concile de Trente, Choisnin suggère tout juste qu'il est responsable de la diversité des religions ${ }^{32}$. Au-delà de la fidélité au texte d'Herburt de Fulstin, cette dernière remarque explique la raison pour laquelle on arrête la litanie des rois à la mort de Sigismond. Il ne faut pas évoquer la mémoire de celui qui, selon Monluc, a provoqué la discorde par son indulgence pernicieuse (cuius indulgentia perniciosor fuit $)^{33}$.

L'élection du fils d'Henri II au trône de Pologne a certes été l'occasion d'une meilleure connaissance de la Pologne. Mais beaucoup d'ouvrages ont ignoré la situation confessionnelle, présentant une image dépassée, figée, voire faussée de la Pologne religieuse. Ces auteurs sont tributaires d'Herburt de Fulstin, dont l'ouvrage vise à occulter tout ce qui porte ombrage à son pays. Mais ils en savent aussi plus sur la Pologne de 1573 que l'ouvrage qu'ils ont décidé de traduire, soit à la lettre comme Beauduin, soit, pour Vigenère, en ajoutant des passages mais sans trahir l'esprit du texte matriciel, à savoir ne rien dire qui nuise à la Pologne. Ces auteurs qui nous informent sur le royaume des Sarmates sont des catholiques dévots comme Belleforest, des catholiques politiquement modérés mais pas catholiquement modérés comme Montaigne ou Vigenère, d'anciens moyenneurs comme Beauduin, et enfin des protestants, comme Esprinchard.

Ce silence montre les limites de la circulation de l'information et remet en question la pertinence de la notion de «modèle » en matière de 
paix de religion. Les manuscrits attestent que le milieu curial français est bien informé des problèmes confessionnels polonais. Le silence de certaines publications résulte donc non pas d'une méconnaissance de la réalité polonaise, mais d'un désir de taire ce qui divise, la réception du concile de Trente ou la tolérance religieuse. Pensons-y toujours, n'en parlons jamais. Ne pas évoquer la division religieuse est le moyen d'éviter le débat sur la manière d'organiser cette cohabitation qui, pas plus en Pologne qu'en France, ne va de soi. L'omission ou le silence « médiatique » constitue une forme de résolution des problèmes.

Mais d'autres auteurs ont opté pour la publication et décrivent avec précision la diversité religieuse. Les cérémonies de l'information n'ont pas toujours pu masquer cette situation, ni éviter de la juger en posant la question de l'attitude que le futur Henri de Valois devait avoir envers ces nouveaux sujets si bigarrés. $\mathrm{Si}$, au XVII ${ }^{\mathrm{e}}$ siècle, cette mosaïque confessionnelle semble faire l'admiration des étrangers, ce n'est guère le cas au XVI siècle chez les Français. Du reste l'éloge de la Pologne multiconfessionnelle émane en général de ceux qui sont minoritaires dans leur pays, calvinistes français ou catholiques anglais ${ }^{34}$.

\section{La Confédération de Varsovie à travers le prisme des divisions confessionnelles}

Rétrospectivement, la Pologne du XVIe siècle apparaît comme un asile pour les persécutés. Déjà, au XVIe siècle, beaucoup de dissidents, traqués, le savaient et décidèrent de s'y réfugier. Certes, il y eut des mesures d'expulsions et il ne faut pas idéaliser cette tolérance entre les religions présentes en Pologne ${ }^{35}$. Malgré ces réserves, la paix semble depuis longtemps nécessaire et mieux pratiquée que « la cohabitation dans l'intolérance » qui caractérise en France les relations entre églises catholiques et réformées à l'époque moderne.

La tolérance polonaise est le fruit d'une tradition historique née de la situation de frontière avec les autres religions, mais aussi avec une hérésie devenue église, le hussisme de Bohème, auquel les Polonais firent appel contre l'ordre teutonique. La nécessité de s'allier avec des hérétiques ou des païens contre l'ordre teutonique, catholique mais ennemi, s'est posée dès le XVe siècle. Cette contrainte a permis au recteur de Cracovie Paul Wlodkowic de poser la question de l'entente avec l'infidèle ou l'hérétique et d'apporter des réponses la justifiant. L'infidèle est aussi un prochain. On ne doit pas faire le mal pour qu'arrive le bien. Il faut refuser la conversion par le « feu et le sang ${ }^{36}$. 
Cette tradition de tolérance culmine avec l'établissement en janvier 1573 de la confédération de Varsovie, qui n'innove pas mais entérine une longue tradition de tolérance que la peur de la Saint-Barthélemy pousse à formaliser, non sans provoquer un âpre débat ${ }^{37}$. Mais le texte de la confédération n'a jamais été publié en France à l'époque, et n'a circulé qu'à l'état de manuscrit dans l'entourage de la cour et dans les milieux diplomatiques ${ }^{38}$. Les protestants furent en France les plus zélés propagandistes de la tolérance polonaise.

\section{Les protestants}

Avant même que la confédération de Varsovie ne soit adoptée, les protestants ont fait valoir l'exemple polonais auprès du roi de France. En 1570, l'électeur de Saxe charge Hubert Languet de venir présenter à Charles IX un projet de ligue anti-espagnole. En chemin, il se joint à l'ambassade des princes allemands envoyée par la diète de Spire féliciter Charles IX sur son mariage avec Elisabeth d'Autriche et sur la conclusion de la paix de Saint-Germain. Languet est chargé par ses collègues de faire la harangue au roi. C'est un plaidoyer pour la liberté de conscience et de culte au cours duquel il vante la coexistence de différentes religions chez le Turc et en Pologne, pays qu'il connaît et où il dispose de nombreux correspondants ${ }^{39}$. Cette harangue a circulé dans les milieux diplomatiques, notamment en Angleterre, avant d'être reproduite par Simon Goulart en 1577 et La Popelinière en 1581. Aussi lorsque la Saint-Barthélemy se produit, Languet, toujours représentant de l'électeur de Saxe, agit en Pologne par l'entremise d'André Dudith, pour qu'Henri de Valois soit écarté au profit du candidat impérial. Pour Languet, la candidature du Valois est une manœuvre papistique. «Par ses intrigues, le pape a obtenu que l'assemblée polonaise préfère le duc d'Anjou au Habsbourg parce qu'il estimait qu'il serait plus rigide que l'Autrichien pour imposer le papisme, craignant que l'empereur ne donne à son fils des conseils de modération ${ }^{40}$. Pour ce diplomate calviniste, le Habsbourg de Vienne, garant de la paix d'Augsbourg, symbolise moins le catholicisme conquérant que le vainqueur de Jarnac ou de Moncontour. C'est aussi la position de Théodore de Bèze qui envoie, mais trop tard, le 30 avril 1573, un proche de Coligny, Rémon, baron de Thyr, expliquer aux Polonais la Saint-Barthélemy et les raisons de ne pas élire Henri de Valois. Bèze estime en mai 1573, que la Pologne, c'est-à-dire la réforme en Pologne, est menacée par deux fléaux : les antitrinitaires et Anjou ${ }^{41}$. Longtemps, Bèze refusera d'admettre l'élection de ce dernier.

Pour permettre celle-ci, Charles IX n'a pas hésité à mobiliser en mars 1573 certains princes protestants allemands comme ses alliés le duc de 
Saxe, le Landgrave de Hesse, et le comte Palatin ${ }^{42}$. En Pologne, Monluc a dû répondre à une campagne de désinformation menée par certains réseaux internationaux protestants, par les compétiteurs du duc d'Anjou, Habsbourg notamment, et par les «mauvais français » dont parle Choisnin, et qu'un mémoire manuscrit de Claude du Bar d'avril 1573 permet d'identifier comme les Rochelais ${ }^{43}$. Diffusant images et libelles en faveur des Valois, Monluc a su déployer devant la diète son éloquence latine, mobiliser d'habiles traducteurs polonais, et utiliser au moment de l'élection la force de l'imprimerie, montrant ainsi que la diplomatie française n'est pas désemparée devant une assemblée aussi nombreuse que la diète polonaise, environ 10000 personnes ${ }^{44}$. Il a aussi déclaré que le duc d'Anjou acceptait la confédération de Varsovie insérée dans les articuli Henriciani, soumis au futur roi, et plus encore les Postulata polonica par lesquelles les protestants polonais exigent de Charles IX des garanties pour leurs coreligionnaires français ${ }^{45}$. Dès le 22 janvier 1573, Monluc avait écrit à Charles IX pour lui suggérer d'atténuer la répression du protestantisme afin de complaire aux Polonais ${ }^{46}$. Mais en avril 1573, Charles IX estime que l'usage de la force s'impose devant des Rochelais dont la rébellion ne se justifie plus que par l'espoir qu'ils escomptent des princes allemands ${ }^{47}$. Peu après l'élection d'Henri, celui-ci, qui se trouvait au siège de la Rochelle, est néanmoins chargé de négocier la fin de la quatrième guerre de religion. L'édit de Boulogne du 11 juillet 1573 mentionne ainsi le rôle pacificateur du roi de Pologne, Henri de Valois, mais ignore l'intervention des ambassadeurs polonais ${ }^{48}$. Il ne faut pas accréditer l'idée qu'une intervention étrangère puisse expliquer la résolution de ce que le roi tient pour une révolte. Selon Stegmann, ce texte fut du reste « le moins appliqué des édits ». Alors certes Agrippa d'Aubigné, évoquant le sort de la Rochelle, loue l'intervention providentielle des «Sarmates rasés » 49. Mais lorsqu'en septembre 1573 , les ambassadeurs polonais invoquèrent de nouveau le sort des protestants français, on les écouta poliment, mais leur ingérence fut peu appréciée et laissée sans suite ${ }^{50}$. Dans toute cette affaire, les diplomates polonais, qui ont débattu des Postulata avec les calvinistes de Genève et Zurich, ont cherché à obtenir des concessions pour les huguenots français, mais pas vraiment à introduire la confédération de Varsovie en France ${ }^{51}$.

De même, lorsque le roi de Pologne revient en France en septembre 1574 et espère encore cumuler les deux couronnes, Innocent Gentillet ne manque pas de présenter le modèle de pacification polonaise, mais là encore, en l'enveloppant de considérations géopolitiques. Faites la paix de religion en France, dit-il en substance au roi, et vos sujets polonais vous en seront d'autant plus reconnaissants et obéissants. La Pologne est moins 
pour les protestants un modèle transposable qu'un moyen de pression politique.

Quant les Polonais entendroyent que vostre majesté auroit bien seurement étably une bonne paix en France au contentement de ceux des deux religions, il est certain qu'ils vous seroyent plus affectionnez et obeissans. Autrement il est bien à craindre qu'ils ne se pourvoyent d'un autre roy. Car leur feu roy Sigismond les a toujours maintenus en bonne paix en l'exercice des deux religions ${ }^{52}$.

Dans ce texte, au côté du Turc et des villes allemandes, la Pologne est incontestablement un exemple réussi de cohabitation confessionnelle. Mais on notera le prisme français et la vision très genevoise de la Pologne. Sous la plume de Gentillet, la paix a été octroyée par le roi de Pologne, ce qui occulte l'accord des Polonais entre eux durant l'interrègne. Ensuite, la situation religieuse polonaise est réduite à un affrontement bi-confessionnel, présenté à l'aune française. C'est aussi ce qu'on retrouve dans les Vindiciae contra tyrannos attribuées à Duplessis Mornay ou à Languet. Les réformés veulent bien promouvoir la confédération mais ils sont gênés devant une paix qui accorde la liberté à plus de deux confessions. D'où la réduction de la situation confessionnelle polonaise à deux religions. Le seul qui échappe à ce dualisme réducteur est Duplessis Mornay qui, aux États de Blois en 1576, déclare : «Les Polonais [...] ont eu de tout temps la religion grecque et romaine [...] De notre temps, il souffre les deux religions qui sont entre nous [...] et plusieurs autres sectes et ne laissent pour cela d'obéir unanimement à leur roi ${ }^{53}$. Mais dans l'ensemble, les réformés ne pouvaient penser le pluralisme polonais au-delà de la situation française. Comme dans tout transfert culturel, il y a mutilation et réappropriation.

Dans les années 1570, la confédération semble moins être pour les protestants français un modèle de tolérance que la Pologne n'est un instrument de pression diplomatique et politique. Gentillet voit dans les guerres civiles l'action des «pensionnaires du pape et de l'Espagnol », et rêve d'une pacification de la France pour permettre une alliance entre la France, la Pologne, et l'Allemagne contre le Turc et le Moscovite ${ }^{54}$. L'intérêt stratégique de la Pologne retient davantage les réformés français que sa situation confessionnelle. La Pologne multiconfessionnelle est donc moins un modèle religieux qu' un moyen inscrit dans la diplomatisation des intérêts confessionnels des réformés. Avec quels succès? Les huguenots, à en croire l'un d'eux, Simon Goulart, semblent avoir été déçus. La publication par Goulart de toutes les harangues prononcées en France et en Pologne vise à dessiller les yeux des gens de bien en confrontant les 
discours et les faits ${ }^{55}$. Tout son ouvrage montre la duplicité du pouvoir royal français, les dangers de l'éloquence, surtout celle de Monluc qui « amielle » les Polonais ${ }^{56}$ et veut démontrer « comment les Polonais étoient maniés » 57 . Au bilan, Goulart est assez dépité et déplore que «les Polonais ne faisoient pas tant pour les Français de la religion qu'il eut été à désirer ${ }^{58}$. La solidarité confessionnelle marque ici ses limites parce que la Pologne reste majoritairement catholique.

\section{Les catholiques}

Cette présentation de la situation polonaise par les protestants ne pouvait que discréditer ses chances d'être prise pour modèle de paix religieuse par les catholiques français. Ceux-ci la discréditent en montrant que la tolérance polonaise conduit à la diversité religieuse, qui signe l'erreur, et que cette tolérance est loin d'être consensuelle et pacifiante en Pologne.

Par le Discours au vray de tout ce qui s'est faict et passé pour l'entrée de l'élection du roy de Pologne publié par Jean Choisnin en 1574, le public peut tout d'abord bien connaître la substance de la confédération et les circonstances de sa conclusion ${ }^{59}$. Proche de Jean de Monluc, Choisnin veut surtout défendre les faits et gestes de l'évêque de Valence, disgracié à son retour en France pour avoir trop facilement accepté les Articuli Henriciani et les Postulata. Dès lors qu'il s'agit de disculper un évêque qui a déjà été suspecté d'hérésie par Rome, on comprend le soin mis par Choisnin à minimiser la complexité de la question religieuse en la réduisant à une opposition entre catholiques et évangéliques, ceux-ci englobant toute la famille protestante.

Mais hormis ce texte, les écrits catholiques sont en général très prolixes sur la scissiparité du mouvement réformé. Outre que cette diversité scelle l'hérésie, elle discrédite la confédération de Varsovie, véritable boîte de Pandore. Ainsi, Le Discours faict sur le royaume de Poloigne, assiette du pais, façons de faire, qualitez, [...], paru à Paris puis à Rouen en 1574, ne cache pas que beaucoup de Polonais ne sont christianisés que depuis peu et que d'autres " vont après leur sens et sous tiltre et pretexte de religion, ont embrassé diverses sectes esquelles ils vivent en liberté de leur conscience ${ }^{60}$. La Cosmographie d'André Thevet signale que «ce peuple est si libertin et plein de sa volonté que de jour en jour les uns se font luthériens, les autres calvinistes, les autres hérétiques et divers en opinions, d'autres hussites, picards (Vaudois), il s'y trouve aussi des Trinitaires qui nient la Trinité » et suivent Servet ${ }^{61}$. Au début du XVII ${ }^{\mathrm{e}}$ siècle, Les estats, empires et royaumes et principautés du Monde de Davity, probablement l'ouvrage de géographie le plus lu en France, est également prolixe sur la présence des hérésies en Pologne. Il accuse Sigismond 
Auguste d'avoir accordé toute liberté aux nobles et présente en définitive avec effroi une Pologne qui «suit l'erreur des Grecs et l'hérésie d'Allemagne ${ }^{62}$. Alors que les protestants simplifient la complexité polonaise pour faciliter l'éclosion de la tolérance civile, les catholiques la présentent dans sa diversité comme pour suggérer que la tolérance conduit au chaos des croyances.

Ensuite, les écrits catholiques présentent la paix de Varsovie comme un accord provisoire, fruit des circonstances et peu consensuel. Ainsi, Choisnin dissimule la peur de la Saint-Barthélemy, qui a accéléré la négociation de cet accord, et préfère souligner le rôle qu'y a joué Monluc. Pour le retour en grâce de son protecteur, il faut ainsi faire valoir ses talents de pacificateur, surtout à l'heure où se réveille en France la cinquième guerre de religion. Monluc est présenté comme celui qui a accéléré la signature de la confédération en montrant aux catholiques réticents que la guerre civile ferait le jeu du Turc ou du Moscovite, et en montrant aux évangéliques que des exigences trop grandes conduiraient à leur ruine. «Ces admonestemens profitèrent beaucoup car il y eut des catholiques qui pour éviter la guerre civille aimèrent mieux signer la confédération esperans que Dieu avec le temps apporteroit quelque remède. Il y eut beaucoup d'évangéliques qui remirent quelque chose de leur aigreur ${ }^{63}$. Ainsi expliquée et présentée, la confédération ne semble être qu'un accommodement provisoire élaboré sous l'égide d'un habile diplomate dont la préoccupation première est de faire élire Henri de Valois. Tant que le traité de la confédération n'est pas signé, l'élection ne peut avoir lieu, ce qui fait le jeu de ses rivaux ${ }^{64}$. Choisnin présente donc Monluc comme un habile manœuvrier, mais nullement comme un apologiste de la solution polonaise. Son objectif reste de disculper de Monluc des articles sur lesquels il nie s'être engagé au nom du roi de France, contrairement aux affirmations des Polonais ${ }^{65}$.

Ensuite Choisnin ne cache pas que la confédération n'est à l'origine le fait que de «quelques uns des catholiques» et que d'autres «n'en vouloient ouir parler » craignant «que cette permission générale ne donna accez à beaucoup d' hérésies et fausses opinions ${ }^{66}$. Il signale l'opposition des évêques. Il avoue que la paix n'est pas acceptée par tous, qu'elle est signée le temps d'une élection et n'est donc que provisoire. La cour de France a pu constater de visu la division des Polonais sur la confédération lorsque, le 22 août 1573, l'évêque de Posnan et quelques autres se sont désolidarisés du reste de l'ambassade en informant Henri de Valois que les catholiques étaient hostiles à cette innovation 67.

Les manuscrits abondent en copie de protestations émises par les autorités catholiques contre la confédération entre mai et septembre 1573, 
notamment celles de l'évêque de Plocen et du primat de Gnesnen. Toutes rappellent qu'elle est contraire à l'obéissance due à l'église romaine, qu'elle attente au droit du roi, qu'elle n'a pas été ratifiée par le sénat et qu'elle a été prise par une assemblée dont la seule mission était d'élire un roi, non de refaire les lois ${ }^{68}$. Une partie du clergé polonais voit dans la confédération la porte ouverte aux sectes et à l'athéisme ${ }^{69}$. Il n'y a pas consensus sur cette paix, notamment de la part du clergé.

Le point essentiel du litige porte sur l'introduction dans le serment du sacre soumis au roi, à l'initiative du palatin de Cracovie, d'une addition qui prévoit que le monarque s'engage « à maintenir et garder la paix entre les différentes religions ». Le pacte de non-agression confessionnelle de la confédération de Varsovie est donc inscrit dans la liturgie du sacre, ce qui de l'avis de certains catholiques polonais ouvre la voix à l'anarchie. Comme en Suisse, la liberté de religion risque d'exciter l'audace des sujets ${ }^{70}$.

Ces réserves ne sont pas cachées dans le secret des missives diplomatiques. Elles s'expriment aussi lors de grandes cérémonies. Lorsque toute la cour de France se retrouve avec Charles IX et le nouveau roi de Pologne à Notre-Dame pour prêter serment de respecter les Articuli Henriciani, l'évêque de Posnan réitère solennellement et publiquement ses protestations contre la nouveauté du serment ${ }^{71}$. Les catholiques polonais sont divisés sur la confédération et les Français le savent et le voient.

Il est accordé plus ou moins de publicité à ces divisions. Lors de la solennelle entrée du roi de Pologne à Paris, le programme iconographique et les inscriptions composées par Dorat sont très laconiques sur la situation religieuse de Pologne, préférant vanter «l'alliance et confédération des deux royaumes », l'amitié des trois frères Valois et Catherine de Médicis la pacificatrice, nouvelle Pallas qui « par trois fois, trois guerres arrêta »72. Cette occultation était inéluctable dans une cérémonie où la ville de Paris a tenu, par un arc de triomphe placé sur le pont Notre-Dame, à manifester l'affection de la cité pour l'antique religion. De même la protestation de certains Polonais à Notre-Dame n'a guère eu d'échos hors des murs de la cathédrale, comme s'il ne fallait pas montrer qu'Henri de Pologne, à Paris, avait prêté serment contre l'avis des catholiques polonais.

En revanche, les différentes pièces relatant la cérémonie du sacre en Pologne et diffusées en France se font l'écho de la confusion qui éclata lorsque le grand maréchal protesta que l'archevêque avait présenté au roi la formule ancienne du serment et non la nouvelle qui comporte la mention de la paix religieuse. Tandis que l'ancienne mentionne l'engagement accoutumé de "maintenir la foi catholique », l'adjonction de «maintenir en paix ceux qui se disputent sur le fait de religion », pacemque et 
tranquilitatem inter dissentes de religione tuebor et manu tenebo, provoque le tumulte ${ }^{73}$. André Thévet relate aussi longuement cet incident qui démontre que le roi a prêté le serment coutumier de «maintenir la foy catholique » puis qu'il a « pour contenter chacun » ajouté qu'il « défendray[t] et meintiendray[t] en paix ceux qui ne sont pas d'accord au fait de religion », suscitant aussitôt un tumulte causé par ceux qui estimaient qu'il n'en faisait pas assez ${ }^{74}$. Les protestants sont présentés comme outranciers dans leurs exigences, et la nouveauté peu consensuelle.

\section{Henri de Valois et la confédération}

Dès lors, les catholiques français se mettent à évoquer le rôle qu'Henri de Valois pourrait jouer en Pologne. On peut très nettement distinguer deux types de publications.

Certaines s'en tiennent à l'image du pacificateur, sans évoquer la religion du prince et la question de la tolérance. Le catholique angevin Victor Du Val vante « la prudente conduite et justice » du nouveau roi de Pologne, pacificateur qui a récemment permis qu'en France «les bons subjects du roy sont restituéz en leur maison et jouissent paisiblement de la liberté de leur religion et des biens spoliez pendant les guerres civiles », allusion à l'édit de Boulogne ${ }^{75}$. Ce qu'il a fait en France plaide pour son élection polonaise et augure bien de son action future. Un autre ouvrage assez curieux présente un tableau synoptique des qualités requises et des défauts dirimants de chaque candidat à la couronne polonaise. Là encore, on glisse sur la question religieuse pour insister sur l'image du vaillant guerrier pacificateur. Pour être élu roi de Pologne, il faut être «bien nourri des lois dès sa jeunesse », «aimer la paix domestique », « ne pas exercer la tirannie domestique ni vouloir opprimer la liberté » ${ }^{76}$. Charles Des Cars, l'évêque de Langres qui accueille les ambassadeurs polonais à Metz au début d'août 1573 s'en tient à cette position lénifiante et évite d'aborder la question religieuse dans sa harangue qui est aussitôt traduite par Jean Bodin et publiée. La paix avant tout.

D'autres textes publiés réclament en revanche un engagement résolu du roi en faveur de l'Église. Ils prolongent ainsi auprès de l'opinion l'effort déployé par des réseaux catholiques très hostiles à la confédération. En août 1573, le cardinal Hosius a ainsi écrit au cardinal Pellevé, archevêque de Sens, pour montrer que le futur roi n'était pas tenu de respecter un serment fait par Monluc à des hérétiques ${ }^{77}$. L'évêque de Poznan écrit au duc de Nevers pour lui dire combien il place d'espoirs dans la venue d'Henri d'Anjou pour rétablir l'autorité du sénat et réduire les choses dans leur état antérieur contre une confédération qui a introduit la tyrannie populaire ${ }^{78}$. Ces propos sont relayés par la publication de certains textes. 
La harangue du cardinal Commendon à la diète a été traduite par Belleforest et publiée en septembre 1573. L'auteur y développe l'idée que la religion catholique et ses évêques ont été les garants de la République polonaise. «Les fondements de vostre liberté sont assis et poséz sur la dignité et grandeur de religion ». Par leur place dans le royaume, les évêques «contiennent le roi en devoir » 79 . Encore faut-il que le roi soit catholique. Puis il fait le procès de ces mots « gracieux mais spécieux » que sont la liberté et la concorde. "La diversité et nouveauté d'opinion » mine la République. Surtout la paix ne peut pas être consentie à n'importe quel prix. "La paix est acceptable par laquelle les torches et feux de division et querelles sont esteinds non celle qui avec une license permise de diverses religions donne et offre de plus grand embrasement et accroit le cœur et hardiesse aux cercheurs de nouvelletez ${ }^{80}$. Ainsi les catholiques français sont informés que la paix de religion provoque la division et la ruine des États, qu'elle prétend pourtant endiguer.

Des écrivains français relaient ce discours. Pour l'auteur du Discours fait sur le royaume de Pologne, publié à Paris et à Rouen, Henri est élu pour entretenir la tradition guerrière polonaise et l' « exaltation de la saincte foy catholique ». Le 24 juillet 1573, lors de son entrée à Orléans, ville meurtrie par les huguenots lors de la première guerre de religion et qui a connu une violente Saint-Barthélemy, le nouveau roi de Pologne, qui est accompagné du duc de Guise, du roi de Navarre, et de Condé, est invité publiquement par deux harangues à extirper l'hérésie en Pologne. Tout d'abord, le président du bailliage souligne que les Polonais l'ont élu car « il a rompu la teste aux serpents, hydres, monstres terribles qui s'estoyent élevés en la France pour effacer ce titre de chrestienté $» 81$. Henri doit de même nettoyer la Pologne. L'évêque d'Orléans, Mathurin de la Saussaye, est plus nuancé mais signale l'attachement des rois polonais à la foi chrétienne en citant le cardinal Hosius.

De fait, pour les catholiques français radicaux, la Pologne, c'est Hosius, cardinal de combat retiré à Rome et dont les ouvrages connaissent, entre 1559 et 1583, 37 éditions en France, dont 14 en français, effectuées par des proches des cardinaux de Lorraine (Nicolas Chesneau, Lancelot de Carle), de Bourbon (Jean de Billy), ou de Tournon. Ronsard apprécie dans le cardinal Hosius un homme «net du fard d' hérésie croyant l'église et non la fantaisie »82. Dans son Des sectes et hérésies de nostre temps et de leur origine, ouvrage adressé à Sigismond-Auguste, traduit par Jean de Billy et publié à Paris en 1561, Hosius se montre farouche partisan d'une intolérance radicale. Il ne faut pas laisser l'hérésie montrer le bout du nez, il ne faut pas autoriser les hérétiques à débattre de la doctrine, car les punir est bien plus utile que de chercher à les convaincre ${ }^{83}$. Dans ses lettres à 
différents personnages de la cour, comme Pellevé ou Morvilliers, chancelier du duc d'Anjou, le cardinal ne cesse de mettre en garde contre la rupture de l'unité de foi qui est une perfidie : quicquid est extra unam fidem non fides sed perfidia est ${ }^{84}$. La confédération est à ses yeux une conjuration contre l'État et la Religion. Après que le roi l'a promulguée, le cardinal ne manque pas de prédire à Morvilliers que la Pologne connaîtra des malheurs comparables à ceux de la France où la pluralité confessionnelle a brisé le corps mystique du royaume ${ }^{85}$.

La situation d'Henri de Valois n'est donc guère confortable. Faut-il, comme il l'a fait, accepter la paix en mécontentant le clergé catholique polonais et des catholiques français radicaux? Ou faut-il sacrifier la paix à la reconquête religieuse? Blaise de Monluc, qui se trouve à ses côtés lors du siège de La Rochelle, note que le nouveau roi de Pologne «n'estoit pas fort content de ce royaume ${ }^{86}$. Jusqu'ici champion du catholicisme intransigeant en France, le voilà revêtant les habits de souverain tenu par un serment de tolérer les hérésies au grand dam d'une partie des catholiques. Son entourage cherche à résoudre cette complexe équation.

Le droit est tout d'abord mobilisé pour essayer de discréditer la confédération. Le très catholique duc de Nevers écrit et recueille un ensemble de textes destinés à guider le nouveau roi de Pologne. Nevers invoque une confédération faite par tous les États à Corchin (Korczyn) en 1438 contre « tous ceux qui voudroient changer la vieille et vraye religion, les faisant inhabiles à toutes dignités, offices, et libertés quelconque ${ }^{87}$. Monluc avait dèjà mis en garde le souverain sur la contradiction qu'il y avait entre la confédération de Varsovie et cette antiqua confederatio ${ }^{88}$. Nevers invoque les anciennes constitutions du royaume et le vieux serment contre les innovations juridiques de l'interrègne. L'exhumation de ces deux serments contradictoires offre une base casuistique pour justifier une évolution ultérieure du roi.

En outre, Nevers estime qu'Henri doit en tout se conformer à ses prédécesseurs : qu'il « ne permette aucunement de changer la religion et le viel ordre que les bons ancestres ont ordonné, principalement la juridicion de l'Estat de l'Église, laquelle estant diminuée de jour en jour [...] estant ce fondement de republique débilité, que le reste du roiaulme ne viennent en ruyne comme l'expérience des aultres roiaulmes nous le demontre ». Pour Nevers, comme pour Hosius ou Commendon, tolérer la diversité religieuse, c'est ébranler l'ordre politique. La confédération est une innovation dangereuse. Le droit légué par l'histoire devient ici l'arme d'une contre-offensive contre la confédération. On comprend dès lors l'intérêt pour l'histoire des rois de Pologne souligné au début de cette analyse et le silence sur le prédécesseur immédiat d'Henri. Le nouveau 
monarque ne doit rien faire d'autre que ce qu'ont fait les rois polonais, à l'exception du dernier, sorte de parenthèse néfaste que ferme Henri. C'est le sens de la réponse de Pibrac, chancelier de Henri, à la harangue de bienvenue prononcée par Karnkowski. Après avoir rappelé qu'Henri a quitté une France pacifiée « pour le présent et pour l'avenir » par ses talents de grand capitaine, Monluc déclare que le roi n'a nullement l'intention de s'écarter de ce qu'ont réalisé ses prédécesseurs. «Par eulx ont été faictes de très bonnes ordonnances : par eulx ont esté establies de très sainctes mœurs et coutumes [...] c'est par eulx que les immunités et franchises perpétuelles ont été baillées aux hommes de l'ordre et estat de chevalerie et noblesse [...] Par quoy il luy semble qu'il ne doit point chercher ailleurs une forme et règle de bien gouverner un royaume que de vostre ancienne usance et des lois anciennement par vous établies desquelles il n'entend jamais s'éloigner d'un doigt ». Dans la tempête il ne faut pas «s'éloigner des coutumes invétéréz au païs ». Pour Pibrac, les anciennes lois auxquelles étaient soumis les rois sont les seules que respectera Henri, ce qui jette l'hypothèque sur les nouveautés votées par des nobles sans roi dans l'interrègne et soumises au nouveau souverain ${ }^{89}$.

Enfin, le serment de respecter la paix de religion n'empêche nullement la possibilité d'agir en monarque catholique. La paix de religion n'est pas la tolérance religieuse. Dans une lettre non datée écrite aux Polonais après son élection, Henri de Valois a rappelé qu'il était catholique et qu'il entendait protéger cette religion, s'efforçant par son exemple et sa parole d'y ramener tous ses sujets. Il précise aussi que cette reconquête ne pouvait se faire dans la discorde, au risque d'affaiblir la Pologne, et au préjudice de la chrétienté et de la France ${ }^{90}$. Monluc lui a effectivement conseillé d'honorer sa religion, de montrer l'exemple pour ramener à l'ancienne religion ses sujets et purger le royaume de l'hérésie et du blasphème. Mais cela ne peut se faire par le feu ou le sang. L'exemple du mauvais roi précédent a conduit aux divisions, le nouveau roi par son comportement exemplaire doit les résorber ${ }^{91}$. La résolution de la division confessionnelle en faveur du catholicisme sera le fruit du charisme princier.

Sans violence, mais sans compromission, le nouveau roi espère rétablir l'unité de religion. Gratiani, secrétaire de Commendon, relate que sur le chemin de Pologne, Henri l'interroge toujours sur la religion des différentes personnes qu'il rencontre ${ }^{92}$. En mars 1574 , l'ambassadeur vénitien Lippomano signale au doge que le roi se montre tous les jours plus catholique et religieux et qu'il en a donné une preuve en refusant d'assister au baptême du fils du palatin de Cracovie parce qu'il était protestant et a préféré aller assister à un baptême catholique ${ }^{93}$. Pour Maciej Serwanski, Henri de Valois a appliqué un programme de reconquête catholique préparé 
à Paris, et j'ajouterais peut-être à Rome, visant à marginaliser les dissidents ${ }^{94}$.

Bref, si les protestants font connaître la paix polonaise et se servent de l'élection polonaise pour faire pression sur la couronne de France, les catholiques apprécient différemment cette confédération. Pour les uns, dont le roi Henri, elle est une concession provisoire. Elle permet de faire la paix de religion dans l'intérêt de la France, de la Pologne et du catholicisme. Mais le monarque a prévenu que cette confédération n'était acceptable que si elle procurait la concorde civile. Si elle la trouble, le roi s'en passera ${ }^{95}$. Or, d'autres catholiques, pour qui la paix ne peut se faire au prix de la tolérance, voient dans la confédération même le germe de divisions futures. Cet accord est contraire aux coutumes ancestrales du royaume, il fait le lit de l'anarchie religieuse et donc de la ruine de l'État. Ces catholiques n'envisagent pas la transposition de la confédération de Varsovie en France mais, au contraire, sa résorption par l'arrivée d'Henri de Valois.

Mais surtout, les publications des catholiques déplacent la question en invoquant l'attitude exemplaire de la noblesse polonaise. S'il y a en effet quelque chose à prendre en exemple en Pologne, c'est la noblesse polonaise et non la paix et la tolérance religieuses.

\section{L'exemplarité de la noblesse polonaise}

Sur ordre de Charles IX, Louis Le Roy traduisit et publia en français la harangue qu'avait faite au nouveau souverain de Pologne un des ambassadeurs polonais, Jean Zamoscie. Les qualités attribuées par le Polonais au nouveau roi, dévot, juste, courageux, comme le désir d'honorer l'ambassadeur justifient cette décision. Mais dans cette occasion, l'auteur a aussi beaucoup insisté sur le patriotisme de la noblesse polonaise, nombreuse, vaillante, indéfectiblement fidèle et obéissante. Le patriotisme de la noblesse y est plus exalté que le catholicisme de la Pologne ${ }^{96}$. En décidant la publication de ce texte, le roi n'a-t-il pas voulu montrer un exemple à ses propres gentilshommes? De fait, les sources imprimées en France et en français s'attardent longuement sur cette exemplarité nobiliaire qui est assez absente des sources manuscrites.

Une autre harangue, également traduite et publiée, celle de Karnkowski, revient aussi à deux reprises sur l'obéissance des Polonais envers leurs rois contre lesquels ils ne se sont jamais révoltés ${ }^{97}$. Le journal de Choisnin peut aussi être lu comme une invitation lancée à la noblesse française pour qu'elle se comporte comme sa consœur polonaise. La tolérance des Polonais est moins une décision juridique que le produit de 
l'amour de la patrie et de l'éthique nobiliaire. Choisnin cite le propos de Saffranies, «gentilhomme de grande authorité » qui lui déclare :

Je suis de la religion qu'on dit évangélique et n'ay délibéré d'en changer : mais j'aimerais mieux mourir cent fois, si tant de fois je le pouvois faire que de prendre les armes pour le faict de la religion contre mon prince. Et voilà pourquoi, puisque je délibère de l'endurer tel que Dieu me le donnera, je désire sur toute chose qu'il ne soit pas taché de cruauté ${ }^{98}$.

Dans sa harangue prononcée devant le roi Charles IX à son retour de mission, Monluc vante aussi l'union et l'intelligence de la noblesse qui a su dépasser la grande diversité de religion « qu'il y a entre eux afin de ne pas se ruiner ${ }^{99}$. Voilà une noblesse qui est vaillante, fidèle à ses rois contre qui elle ne s'est pas soulevée depuis cinq cents ans, et qui, bien qu'ayant le droit d'élection, a toujours reconduit fidèlement les Jagellon, jusqu'au dernier. Choisnin rajoute que cette noblesse ne grève pas la monarchie de pensions ni de gratifications. André Thevet décrit à son tour une noblesse égalitaire, sans inféodation clientéliste, où " le roy seul commande à qui que ce soit », où le roi est seul maître de la faveur et de la justice distributive. Cette république nobiliaire où « un gentilhomme polonais a presque la même liberté et authorité qu'avait jadis un citoyen romain » est obéissante, pacifique, vaillante, responsable, unie ${ }^{100}$. La Pologne est, sous le regard de ces Français, une utopie nobiliaire, non religieuse. Toute la noblesse y seconde son roi.

La paix de religion n'est pas ici une construction juridique ni de juristes. Elle ne peut s'obtenir en modifiant les lois et les modes de gouvernement, mais en exaltant la fraternité et l'amitié qui unissent la noblesse. En France, à l'époque, ce groupe social n'est pas une catégorie définie juridiquement mais une production sociale taisible, où la durée, la lignée et la virtu héritée et personnelle confèrent la qualité nobiliaire. L'amitié, qui, en France, fractionne la noblesse en clientèles, a une fonction égalisatrice et unificatrice en Pologne ${ }^{101}$. Certes les Malcontents en France se réclament aussi de cette amitié fédératrice qui transcende les clivages religieux ${ }^{102}$. Mais ces Malcontents sont aux yeux du roi des séditieux. La confédération de Varsovie offre le modèle alternatif d'une amitié nobiliaire dans la fidélité au roi. Aucun texte publié alors en France n'a jamais présenté la confédération comme une conjuration ainsi que l'a fait Hosius dans le secret de ses épîtres ${ }^{103}$. Le dictionnaire de Cotgrave atteste que le complot est un des synonymes du mot confederatio.

Mais ce terme est peu en usage en France au XVIe et jamais avec cette connotation négative de conjuration. Le dictionnaire Français-Latin de Robert Estienne paru en 1549 l'ignore tout comme le premier dictionnaire 
Latin-Franco-Polonais paru en France en $1586^{104}$. Jean Thierry signale certes en 1564 les mots confédérer et confédération mais est incapable de fournir la moindre expression les employant, indice d'un usage limité ou censuré105. Il faut dire qu'imprégnés du latin classique, ces dictionnaires manquent de mot pour dire, comprendre, voire admettre le présent ${ }^{106}$. Le mot confédération est toutefois employé dans la langue française depuis les années 1530, au sens d'alliance amoureuse, de première épouse (prime conjuga $)^{107}$. Edmond Huguet en recense peu d'occurrences, mais confirme que le terme relève alors de l'union amicale ou amoureuse. On parle de la confédération de Varsovie comme de la confédération de la France et de la Pologne, comme d'une alliance amicale. Pour Brantôme, un confédéré est un compagnon. C'est du reste le sens que Du Cange donne au mot latin confederativus au début du XVII ${ }^{\mathrm{e}}$ siècle ${ }^{108}$. Le réseau notionnel et lexical gravitant autour du terme confédération et son application à la résolution des conflits civils d'origine religieuse n'induit nullement de la part des contemporains le recours à une construction juridique. Pour Jean Thierry, confédération renvoie à fredus, à l'alliance, au pacte, au serment. C'est donc l'amitié, créatrice du lien social, l'amitié, cette éminente valeur humaniste, citadine et nobiliaire que les Polonais maîtrisent à la perfection, qui leur permet de surmonter les antagonismes confessionnels ${ }^{109}$.

C'est donc sur ce terrain amical, et non sur celui du droit et de l'autonomie du politique, que l'humaniste Pibrac place les relations entre Henri et sa noblesse polonaise. Entre le roi et la république, l'union est comme «l'alliance et union sacro sainte du mariage ». La Pologne est épouse du roi et « le principal et vrai douaire d'une république est l'amour et dilection des vassaux et sujets d'un prince ». La harangue s'achève par l'affirmation que la paix n'est pas affaire de nouvelle loi, mais résulte d'une «commune affection » et d'une «amitié mutuelle » entre le roi et la noblesse, presque mise sur le pied d'égalité que les époux ou les amis partagent entre eux ${ }^{110}$. L'amour et le service du roi dépassent tous les antagonismes.

La confédération de Varsovie est donc avant tout présentée comme le fruit d'un serment, adossé à la fides, et reposant sur la confiance, la fiducia . C'est là un concept qui lie en gerbe des rapports de types personnels, matrimoniaux, féodaux ou religieux ${ }^{111}$. Ce serment pourrait être conçu comme le fruit d'un amour civique du bien public, d'inspiration cicéronienne, et sembler affranchi du religieux sans pour autant être politique, au sens très juridique que revêt ce terme à l'époque ${ }^{112}$. Mais ce serment peut aussi procéder d'une démarche chrétienne en étant un sacramentum qui prend Dieu à témoin. Le fait qu'il soit horizontal, passé entre égaux, et non établi sur le modèle féodal du serment vertical n'est pas en effet un élément suffisant pour penser ce serment comme une sortie de la sphère reli- 
gieuse ${ }^{113}$. C'est sur les Évangiles qu'Henri de Pologne a prêté serment de garantir la confédération. Un extrait des Essais de Montaigne démontre amplement que le serment de maintenir la paix, adopté par les membres de la diète d'élection polonaise, s'inscrit aux yeux des Français dans une conception sacrée des rapports humains. Le chapitre 14 du livre I a été rédigé vers 1572, au moment où s'établit justement la confédération de Varsovie. Ce chapitre vise à démontrer que notre bonheur et notre malheur dépendent moins des choses en elles-mêmes que de l'opinion que nous nous en faisons. Ainsi la souffrance physique est largement tributaire du plus ou moins grand contentement que l'homme place en son âme. Parvenu à ce stade de son raisonnement, Montaigne rapporte que le roi Henri III lui a raconté qu'en Pologne il est de coutume de «se blesser à escient pour donner foy à [sa] parole »114. La souffrance physique vient ici authentifier et certifier l'engagement. Et immédiatement après cette référence polonaise, Montaigne enchaîne sur la religion chrétienne qui offre aussi de notables exemples de saints supportant la douleur par et pour la foi, au premier chef desquels il désigne... saint Louis. Cette proximité textuelle du serment en Pologne et de la mortification dans la foi religieuse me semble significative d'une appréhension encore très religieuse de ce geste.

Contemporaine de la confédération de Varsovie, cette digression de Montaigne montre la réception du serment par les Français. Il reste affaire de foi, non de loi. Ainsi présentée, la confédération de Varsovie est tout à fait acceptable pour les catholiques français attachés à l'unité sinon à l'uniformité du christianisme, car la cohabitation confessionnelle n'est pas l'expression d'une autonomisation du politique mais l'attachement à un ordre chrétien où coexistent indissolublement politique, religieux et social. L'amitié pacifiante des nobles et du roi, fondée sur un serment d'essence sacrée permet de dépasser les querelles confessionnelles et leurs non moins conflictuelles tentatives de résolution dans le cadre d'une codification juridique que d'aucuns jugent illégale et illégitime.

Cet ample éloge de la noblesse polonaise, de l'amitié et de la fidélité qu'elle cultive est enfin une réponse aux nobles malcontents et aux monarchomaques qui, en France, se rebellent sous le manteau de religion, en évoquant notamment la constitution polonaise emblématique de cette monarchie mixte, garante de la paix de religion ${ }^{115}$. Or, pour l'entourage d'Henri de Valois, si la confédération est louable en tant qu'expression de l'amitié des nobles entre eux et avec le roi, elle est en revanche inacceptable si elle veut réduire son pouvoir à celui d'un duc de Venise ${ }^{116}$.

Pour les protestants français, la confédération de Varsovie est le produit d'un modèle politique polonais, à savoir une monarchie à la souveraineté mitoyenne, une monarchie mixte, chère aux protestants, à 
certains nobles catholiques et à une historiographie de la genèse de l'État moderne qui procède à la recherche généalogique des anticipations de notre modernité constitutionnelle ${ }^{117}$. Les monarchomaques, indignés par la Saint-Barthélemy, n'ont pas manqué d'invoquer la situation polonaise. Gentillet ne fait pas l'apologie de la tolérance polonaise en soi mais montre qu'un roi ne peut faire la guerre à ses sujets en ordonnant un massacre. L'auteur des Vindicia contra tyrannos se sert de l'exemple polonais pour montrer que partout les peuples font les rois, qu'aucun impôt, aucune nouvelle loi ne peuvent y être adoptés sans le consentement des États Généraux. Et s'il évoque le serment fait par Henri de Valois lors de son sacre polonais de maintenir la paix de religion, c'est moins pour exalter la cohabitation confessionnelle que pour défendre l'universalité de l'inviolabilité du serment ${ }^{118}$. La coexistence des cultes est adossée dans les nombreux écrits protestants des années 1570 sur le respect des traditions constitutionnelles du royaume tandis que l'intolérance est le produit d'un tyran mal conseillé. Dans ce contexte de légitimation de la résistance des huguenots français et d'élaboration de la tolérance polonaise, Théodore de Bèze rédige $D u$ droit des magistrats paru en français pour la première fois en 1574 et qui connaîtra dix éditions entre 1574 et 1579 . Les Polonais figurent parmi les «exemples des devoirs des sujets envers le souverain légitime estant devenu tyran manifeste », car ils ont su bien régler et limiter la puissance de leur monarque ${ }^{119}$. Mais c'est Agrippa d'Aubigné qui, dans les Tragiques, écrits principalement entre 1577 et 1589, laisse le mieux percer son engouement pour la Pologne de l'interrègne au deuxième livre appelé Princes :

«Ah! Sarmates rasés, vous qui étant sans Rois

Aviez le droit pour Roi et vous-mêmes pour lois

Que dedans l'interrègne observiez la justice

Par amour de vertu, sans crainte de supplice

Quel abus vous poussa pour venir de si loin

Priser ce méprisé, lorsqu'il avait besoin

Pour couvrir son malheur d'une telle aventure ${ }^{120}$.

Agrippa n'est pas républicain, la préface au lecteur en témoigne, mais il est contre la tyrannie qu' incarne l'un des acteurs de la Saint-Barthélemy. Sa Pologne est exemplaire d'un fonctionnement politique fondé sur la vertu, non sur la religion, et où la loi s'impose au roi, où elle se fait même en l'absence du roi, prétention inadmissible pour la monarchie française qui répond à cette lecture protestante constitutionnaliste de la Pologne par l'exaltation d'une cohésion sociale fondée sur l'amitié sacrée entre le roi et les nobles polonais. 
Ce modèle de la monarchie mixte, meilleure garantie de la paix de religion est toutefois peu à peu abandonné par les protestants français. Cette évolution tient au fait que les États Généraux tant réclamés par les monarchomaques ont effectivement été convoqués par Henri III, mais pour résorber les concessions faites lors de la paix de Monsieur. Puis la monarchie mixte et les États Généraux ont été réclamés, défendus, convoqués et noyautés par la Ligue, hostile à toute tolérance de l'hérésie et à toute autonomie du politique. Dès lors, les protestants n'attendent plus leur salut d'une monarchie mixte mais d'un roi absolu, celui des Politiques, d'un roi détenteur d'une souveraineté qui ne se partage pas. Il est significatif que Du droit des magistrats de Bèze ne soit plus réédité après 1581. Ces raisons ont peut-être détourné les protestants de continuer de se référer à la Confédération de Varsovie. L'enquête resterait à faire pour le XVIIe si ècle.

Ambroise Jobert, suivant sur ce point Jean Leclerc, écrit que « jusqu'au milieu du XVII e siècle la Pologne fut considérée à l'étranger comme un modèle de tolérance ${ }^{121}$.

Or nous avons montré que beaucoup d'ouvrages ignorent la tolérance polonaise. Les catholiques intransigeants, animés par des prélats polonais, jugent la confédération néfaste à l'État comme à la Religion. Les protestants se servent moins de la Pologne comme un modèle que comme un moyen de la diplomatisation des relations confessionnelles. Il faut ensuite déterminer ce qui fait modèle et pour qui. C'est cette Pologne au prisme français que nous avons cherché à reconstruire. Pour les protestants français et certains nobles catholiques, c'est moins la tolérance en soi qui fait modèle chez les «Sarmates » que la monarchie tempérée dont ils attendent la paix de religion du moins jusque vers 1585 . Au contraire, pour d'autres catholiques, la Pologne offre un modèle d'amitié nobiliaire propice au bien public et éloignée de l'amitié factionnelle de la noblesse française. Bref, on aborde peu la question de la tolérance polonaise dans les écrits français du $\mathrm{XVI}^{\mathrm{e}}$ siècle : certains ouvrages décrivent la constitution polonaise, d'autres l'amitié et la fidélité nobiliaire, d'autres enfin la force chrétienne du serment.

Enfin, lorsque la tolérance est un modèle, pour qui l'est-elle? Pour le catholique ou le protestant, le minoritaire ou le majoritaire? Ambroise Jobert est bien en peine de citer un seul autre témoignage d'un catholique en position majoritaire, que celui du cardinal Ossat qui invoque la situation polonaise pour encourager Clément VIII à entériner l'édit de Nantes. Les seuls catholiques à invoquer le modèle de tolérance polonaise sont ceux qui vivent dans l'intolérance et en situation minoritaire, en Angleterre ou en Hollande. De fait, nous avons pu constater que la confédération de Varsovie est loin de séduire les catholiques français : tout d'abord parce 
qu'elle est défendue par les protestants, ensuite parce qu'elle ouvre à l'anarchie des croyances, enfin parce qu'elle est associée à une modification de la constitution polonaise et à une innovation, avec tout ce que ce terme a alors de péjoratif. L'avenir de cette paix semble précaire. On n'en parle donc guère sinon pour en montrer les conséquences affligeantes.

La confédération de Varsovie ne s'inscrit donc pas dans une «série d'imitations croisées » qui caractériseraient les paix de religion. Il n'y a pas imitation mais interaction. Le transfert de l'information est dissymétrique. La Saint-Barthélemy a certainement eu plus de conséquences en Pologne que la confédération de Varsovie n'en a eu en France. La peur d'une reproduction d'un massacre en cas d'élection d'un Valois a joué un grand rôle dans la formalisation de la confédération de Varsovie. La peur de la « furie française » pour reprendre les termes du De furoribus gallicis d'Hotman a été la contribution indirecte et involontaire de la France à la tolérance polonaise. Cette crainte est nourrie par des relais polonais en France (étudiants polonais à Paris, Orléans ${ }^{122}$ ), par des mauvais Français en Pologne, comme les nomme Choisnin, et par la propagande Habsbourg qui fait tout pour disqualifier le candidat français en mettant en avant que le Habsbourg est garant de la paix civile en Allemagne. Le Habsbourg impérial n'incarne pas alors la même politique que son cousin madrilène sur la scène internationale.

Enfin cette étude est une invitation à éviter les lectures téléologiquement orientées vers l'impératif de contemporanéité que s'assigne volontairement ou inconsciemment l'historien, soumis - d'une servitude volontaire - au devoir de mémoire et au rythme des commémorations nationales. J'ai voulu restituer la pluralité des discours et des perceptions que les Français contemporains ont fait de cet évènement polonais afin de restituer leur horizon d'attente devant une histoire qui n'est pas encore écrite dans ces années 1570. En l'occurrence, le terme de confédération de Varsovie dans la langue française du XVIe ne semble guère renvoyer à un modèle politique, sinon chez des protestants minoritaires. Mais pour la plupart, la résolution du conflit religieux ne passe pas par une solution de type politique et constitutionnelle. Pour beaucoup de Français, la paix polonaise est affaire de mœurs plus que de lois, de comportement chrétien et/ou cicéronien - plus que de constitution, de circonstance plus que d'avenir. Cette paix établie dans un interrègne semble même peu à peu irrecevable pour les Politiques, partisans d'un pouvoir royal fort, et capables de placer le roi au-dessus des partis nobiliaires, des confessions et des églises.

L'historien est donc confronté au risque d'effectuer des réflexions anachroniques sur les modèles étatiques centralisés ou de types fédéralis- 
tes, les plus aptes à garantir la paix de religion ${ }^{123}$. C'est ce réductionnisme en science politique que nous avons cherché à éviter en historicisant les pratiques et les catégories d'analyse du temps.

\section{Université de Paris I}

\section{Notes}

1. Maciej Serwanski, « Henri de Valois au trône de Pologne : les problèmes de la tolérance religieuse et la politique au XVI siècle », Renaissance européenne et phénomènes religieux, 1450-1560, Montbrison, Association du Centre culturel de la ville de Montbrison, 1990, p. 304.

2. Janusz Tazbir, A State without stakes: Polish religious toleration in the sixteenth and seventeenth centuries, Varsovie, Kosciuszko Foundation, 1973.

3. Maciej Serwanski, Henryk III walezy $w$ polsce. Stosunki polsko-francuskie $w$ latach, 1566-1576, Wydaw, Literackie, 1976. Cet ouvrage qui comporte un résumé en français inscrit l'élection d'Henri de Valois dans le contexte international. Le royaume de Pologne craint de suivre le sort de la Bohème ou de la Hongrie, une annexion par les Habsbourg.

4. La bibliographie sur le sujet est abondante depuis le marquis Emmanuel Henri Victurnien de Noailles, Henri de Valois et la Pologne en 1572, Paris, 1867, 3 vol. Le troisième comporte près de 600 pages de sources en latin, en français, en polonais et en italien.

5. Marc Venard, «La présentation de la Saint-Barthélemy aux Polonais », Les contacts religieux franco-polonais du Moyen Age à nos jours, Colloque de Lille, 1981, Paris, CNRS, 1985, p. 116-27.

6. Janusz Tazbir, «Les guerres de Religion françaises vues par les Polonais », Les contacts franco-polonais du Moyen-Àge à nos jours, p. 129.

7. C'est le parti adopté par Jean Béranger, Tolérance ou paix de religion en Europe centrale 1415-1792, Paris, H. Champion, 2000.

8. Michel Espagne, Les transferts culturels franco-allemands, Paris, PUF, 1999, p. 35.

9. Maurice Halbawchs, La mémoire collective, Paris, PUF, 1968, p. 100. « On rapproche des évènements qui n'ont aucune action l'un sur l'autre...Il importe peu que des faits se soient produits la même année si cette simultanéité n'a pas été remarquée par les contemporains ».

10. Dans un stimulant article sur le déclin de la fascination française pour le modèle constitutionnel Sarmate au XVIIe, l'un des meilleurs spécialistes français de l'histoire polonaise, Daniel Tollet n'a pas abordé la question religieuse. «La Pologne vue par les Français fin XVIe-XVIIe siècles », L'Etat baroque, dir. Henri Méchoulan, Paris, J. Vrin, 1985, p. 447-54. On ne trouve pas plus d'information dans François Rosset, L'arbre de Cracovie. Le mythe polonais dans la littérature française, Paris, Imago, 1996.

11. Daniel Tollet, Les Polonica de la bibliothèque nationale, Paris, La Bibliothèque, 1982.

12. Ambroise Jobert, De Luther à Mohila : La Pologne dans la crise de la chrétienté, Paris, Institute d'études slaves, 1974, p. 28.

13. Maciej Serwanski, « Henri de Valois au trône de Pologne », p. 301.

14. Ambroise Jobert, op. cit., p. 152-53. 
15. Hosius, Des sectes et hérésies de notre temps et de leur origine, Paris, 1563, p. 23, 58.

16. Le catalogue informatique de la BNF ne donne que deux éditions parisiennes de Martin Cromer, De falsa lutheranorum sive evangelicorum nostri temporis, G Guillard, Paris, 1560 et Epistolae duae insignes... Paris, 1564. Cromer a envoyé sa Polonia à Henri III via Karnkowski. Michel François, Lettres de Henri III, roi de France, Paris, C. Klincksieck, 1959-, t. 1, p. 299.

17. François de Belleforest, Cosmographie universelle, Paris, 1575, t. 1, 2e vol., p. 1778 sq. La Cosmographie de Belleforest parait avec celle de Thevet; cette dernière est beaucoup plus riche en informations pour notre sujet, mais eut moins de succès que celle de Belleforest. Frank Lestringant, André Thevet cosmographe des derniers Valois, Genève, Droz, 1991, p. 231. F. Lestringant considère que le succès de Belleforest tient à ses larges développements sur la France et surtout au fait que Thevet n'apporterait rien de neuf hormis sur l'Amérique. Je ne partage pas ce point de vue si l'on se réfère au développement sur la Pologne où Thevet est plus riche que Belleforest.

18. François d'Amboise, 1550-1620, sera régent de Navarre, puis avocat au parlement de Paris, conseiller au parlement de Bretagne et conseiller d'État en 1604. Poète, traducteur, il s'est déjà fait connaître avant la Pologne par une Élégie sur le trépas du connétable de Montmorency et par un Hymne triomphal au roi, après la victoire sur les huguenots en 1568. La Pologne a été rééditée dans François d'Amboise, CEuvres complètes, t. 1, 1568-1584, éd. Dante Ughetti, Naples, Edizioni scientifiche italiane, 1973, p. 130-45.

19. Denyse Métral, Blaise de Vigenère, archéologue et critique d'art (1523-1596), Paris, E. Droz, 1939.

20. Jerzy Kloczowski, Muriel Wosniewski, « Les premières histoires de la Pologne publiées en France », Henri III et son temps, éd. Robert Sauzet, Paris, J. Vrin, 1992, p. 107.

21. Blaise de Vigenère, La description du royaume de Pologne, Paris, 1573, p. 13, 22, 33, $38,68-69,73,81-82$.

22. T. Wyrwa, « Politique et religion en Pologne au temps de la Réforme », Revue historique, t. 263,1980 , p. 72.

23. Blaise de Vigenère, op cit., p. 43, 48.

24. Ambroise Jobert, op. cit. p. 39.

25. Janusz Tazbir, Poland as the rampart of Christian Europe : myths and historical reality, Varsovie, Interpress, s.d.

26. Voir le poème «Adieu à la Pologne », Philippe Desportes, Les premières auvres de Philippe Des Portes au roy de France et de Pologne, Paris, 1585, p. 278-80.

27. J Morawski, La Pologne vue par deux voyageurs français au XVIe siècle, Paris, s.d., p. 707.

28. Leopold Chatenay, La vie de Jacques Esprinchard rochelois et journal de ses voyages, Paris, SEVPEN, 1957, p. 144.

29. Jerzy Kloczowski, Muriel Wozniewski, op. cit., p. 105.

30. Blaise de Vigenère, Les chroniques et annales de Pologne, Paris, 1573, p. 482.

31. Blaise de Vigenère a été chargé par Catherine de Médicis de négocier à Rome la succession de Sigismond Auguste. Cette mission l'a rendu familier des affaires polonaises. 
32. Jehan Choisnin, Discours au vray de tout ce qui s'est faict et passé pour l'entière négociation de l'élection du roy de Pologne, Paris, 1574. J'utilise l'édition donnée à Paris en 1823 par Petitot, p. 204.

33. BNF, ms. fr. 3259 , fo $30 v^{\circ}$.

34. Janusz Tazbir, La république nobiliaire et le monde. Etudes sur l'histoire de la culture polonaise à l'époque baroque, Wroclaw, Ossolineum, 1986, p. 181-88.

35. À Leopol, il y a un archevêque catholique, un prélat grec et un autre Arménien, tous nommés par le roi. Mais seuls les catholiques ont le droit de bourgeoisie et il est interdit aux Grecs de sonner les cloches et leurs processions sont très réglementées. Les juifs ont été expulsés en 1495, comme en Castille ou en Provence, mais ils ont été rappelés en 1503. Ambroise Jobert, op. cit., p. 33-35.

36. Tadeusz Wyrwa, «Les idées de tolérance religieuse en Pologne au seuil des temps modernes », Les contacts religieux franco-polonais du Moyen Age à nos jours, Colloque de Lille, 1981, Paris, CNRS, 1985, p. 107-16.

37. Ibid., p. 74.

38. Gilles de Noailles, abbé de L'Isle, a envoyé le texte de la confédération le 17 mars 1573, dans une traduction latine faite à partir du polonais par les jésuites, et traduite ensuite en français par de L'Isle. Celui-ci signale que les jésuites « ont de bon cœur travaillé » à cette traduction. Les jésuites ont donc à cœur de diffuser la paix polonaise. Mais on doute fort que ce soit pour l'ériger en modèle. Le censeur est aussi un diffuseur. Noailles, op.cit. t. 3, p. 242.

39. Béatrice Nicollier-De Weck, Hubert Languet (1518-1581). Un réseau politique international de Melanchton à Guillaume d'Orange, Genève, Droz, 1995, p. 247-48, 253.

40. Ibid., p. 324.

41. Théodore de Bèze, Correspondance, Genève, Droz, 1990, t. 14, p. 94, 114. Peut-être s'agit-il du baron de Thye, Remon, qui était au côté de Coligny quelques jours avant sa mort et qui arriva en Pologne après l'élection d'Henri. Janusz Tazbir, «La nuit de la Saint Barthélemy, ses échos en Pologne », L'amiral de Coligny et son temps, Paris, Société de l'histoire du protestantisme français, 1974, p. 430.

42. BNF, ms. fr. 15967 , fo 3,7 .

43. BNF, ms. fr. 16936, fo 48.

44. Les moyens utilisés par les différents ambassadeurs devant la diète polonaise conduisent à nuancer l'affirmation d'Alain Tallon qui considère que la personnalisation des relations diplomatiques est telle au XVIe siècle qu'elle explique « le malaise qu'éprouvent les ambassadeurs quand ils ont à traiter avec une collectivité comme l'est un concile ». Alain Tallon, La France et le concile de Trente 1518-1563, Rome, École Française de Rome, 1997, p. 23. L'expérience conciliaire a probablement familiarisé les diplomates aux usages des discussions avec les assemblées pléthoriques.

45. Théodore de Bèze envoie un pasteur du refuge d'Orival auprès des ambassadeurs polonais pour les inciter à bien défendre les protestants français. Théodore de Bèze, Correspondance, t. 14, p. 283. Ces Postulata ex nobilitate evangelicam religionem ont été publiées par Noailles, op. cit., t. 3, p. 409-11. Le premier article exige la réhabilitation de la mémoire des victimes de la Saint-Barthélemy, le deuxième la possibilité de vivre tranquillement partout dans le royaume. Le troisième réclame la possibilité d'émigrer et de pouvoir partir avec le prix de ses biens. Le quatrième et le sixième réclament la 
restitution des biens aux enfants des victimes ou aux proscrits. Le cinquième, la poursuite des auteurs du massacre. Le septième et le huitième réclament la liberté d'exercice de culte. Les Postulata ont été rendues publiques par Simon Goulart. Ambroise Jobert, op. cit., p. 185.

46. Noailles, op. cit., t. 3, p. 220. «Ceux de la Rochelle méritent bien tous les maux du monde, mais si pour une si grande occasion que ceste icy, vous pouviez différer la pugnicion qu'ils ont méritée...vous feriez beaucoup pour monsieur votre frère ». Il est significatif de constater que dans cette lettre, Monluc n'évoque pas la confédération qui vient d'être signée entre Polonais, mais le sort des protestants français.

47. BNF, ms. fr. 15967 , fo $5 \mathrm{v}^{\circ}$.

48. André Stegmann, Édits des guerres de religion, Paris, J. Vrin, 1979, p. 86-93.

49. Agrippa d'Aubigné, Les Tragiques, «Les Fers », Euvres, Paris, Gallimard, 1969, p. 181.

50. Noailles, op. cit., t. 2, p. 369.

51. Sur le rôle de Zurich et Genève voir Maciej Serwanski, « Henri de Valois au trône de Pologne », p. 306-7.

52. Innocent Gentillet, Remonstrance au roy très chrétien Henri III roy de France et de Pologne sur le faict de deux édits de sa majesté touchant la paix, Francfort, 1574, p. 105.

53. Ambroise Jobert, op. cit., p. 187.

54. Innocent Gentillet, op. cit. p. 105-7. À noter que Coligny lui aussi rêvait d'une même alliance mais visant à marginaliser, voire à combattre les Habsbourg aux Pays-Bas.

55. Simon Goulart, Mémoires de l'état de France sous Charles IX, 1578; t. 1, p. 6.

56. Ibid., t. 2, p. $268 \mathrm{v}^{\mathrm{o}}$.

57. Ibid., t. 2, p. 325.

58. Ibid., t. 3, p. $12 \mathrm{v}^{\mathrm{O}}$.

59. Le contenu de la confédération est dans Jehan Choisnin, p. 121-22.

60. Discours faict sur le royaume de Poloigne, assiette du pays, façons de faire, qualitez, richesses, forces, Rouen, 1574, fo b3.

61. André Thévet, Cosmographie universelle, Paris, 1575, t. 2, p. 878. Le ci-devant cordelier Belleforest a jeté la suspicion sur le catholicisme de Thevet. Frank Lestringant a montré que le cordelier sécularisé Thevet était passé d'une sensibilité érasmisante, puis luthérienne masquée à un conformisme catholique qui le conduit à se placer dans le camp de la Ligue et à être tenu par les Politiques pour espagnolisé. Dénoncé comme athée par Belleforest, visé par les calvinistes, Thevet est avant tout cosmographe. Concernant la Pologne, où Thevet ne s'est pas rendu, l'approche du cosmographe du roi est différente de celle de Belleforest. Il commence par la Pologne puis seulement viennent les rois qui occupent toutefois plus de place que la description des peuples, des religions, des mœurs, de l'économie et des villes polonaises. L'information ne s'arrête pas à la moitié du XVIe et il cite des évènements de $1567,1571,1573$. Sa description de la situation religieuse est beaucoup plus riche et actualisée que celle de Belleforest. Assez hostile aux orthodoxes, sympathisant des Tatares mahométans ou idolâtres qui refusent de se convertir «veu la méchanceté de plusieurs de ceux qui suyvent la loy chretienne» (p. 882), Thevet ne décrit toutefois pas la diversité confessionnelle polonaise dans une optique bienvaillante. En citant tout d'abord Génébrard qui a réfuté les antitrinitaires polonais (p. 878), le même Génébrard qui a justement accordé l'imprimatur de la faculté de théologie pour la 
Cosmographie, puis en plaçant le portrait d'Hosius et en faisant l'éloge de celui qui s'est opposé aux « opinions nouvelles que l'on commençoit à introduire en Pologne », le cosmographe en titre des derniers Valois choisit le camp catholique. Certes il précise que les rois ont « enduré jusqu'à présent » cette diversité d'opinions dès lors que l'impôt est payé et la paix respectée. La tolérance civile n'est pas sympathie religieuse. Les rois supportent, tolèrent, mais provisoirement.

62. Davity, Les estats, empires et royaumes et principautés du monde, Genève, 1665, p. 510-12. Sur la diffusion de Davity, voir Henri-Jean Martin, Livre, pouvoir et société à Paris au XVII siècle (1598-1701), Genève, Droz, 1969, t. 1, p. 511.

63. Jehan Choisnin, Discours au vray de tout ce qui s'est faict et passé pour l'entière négociation de l'élection du roi de Pologne, éd. Petitot, Paris, 1823, p. 143.

64. Ibid., p. 142.

65. Ibid., p. 164.

66. Ibid., p. 121-22.

67. Noailles, op. cit., t. 3, p. 466.

68. Sur la protestation de Gnesnen, BNF, ms. fr. 5145, fo 181-83 ou ms. fr. 3258, fo 26-27. Sur celle de Plocen, ms. fr. 15967, fo 129-34.

69. BNF, ms. fr. 5145, fo 164.

70. BNF, ms. fr. 5145 , fo 164 . ms. fr. 3258 , fo 70.

71. Noailles, op. cit., t. 2, p. 367.

72. Registre des délibérations du bureau de la ville de Paris, éd. F. Bonnardot, Paris, t. 7, 1893, p. 114-20. Une seule inscription placée rue Saint-Antoine sous les armoiries de Pologne évoque l'engagement du roi de faire régner la paix, sans cependant évoquer la question confessionnelle. Sancta jura dabo pacemque meis et foedera honores servabo atque suos genti tutabor.

73. Gelée de Villemontée, Les obsèques et funérailles de Sigismond... plus l'entrée sacre et couronnement de Henri, Paris, 1574, fo b4vo.

74. André Thevet, op. cit., t. 2, p. 893.

75. Victor du Val, Congratulation et réjouissance sur la grande et inespérée nouvelle advenue de l'élection de monsieur, Paris, 1573. Il y a aussi une édition lyonnaise.

76. L'ordre tenu et gardé par les potentats et seigneurs polonais en l'élection de très illustrissime duc d'Anjou, Paris, 1573.

77. « Ne se putet obligatam juramenta qua praestitit haereticis Monlucus sed ea revocet». BNF, ms. fr. 15967, fo 68 .

78. « No posso pensare megliore remedio che fa venuta di su majesta l'authorita tel quale giunta con la potentia del senato potra redute gli cose nel pristino stato ». BNF, ms. fr. 3259 , fo $104 \mathrm{r}^{\circ}$.

79. Jean François Commendon, Harangue de l'illustrissime et révérendissime Jean François Commendon, cardinal, légat collatéral du Saint-Siège en Germanie et Poloigne, Paris, 1573 , p. 6.

80. Ibid., p. 9.

81. Nicolas Rousseau, Discours de l'entrée du roi de Pologne faicte à Orléans, Orléans, 1573, p. 43. 
82. Ambroise Jobert, «Editions et traductions du cardinal Hosius en France », Mélanges Latreille, Lyon, Audin, 1972, p. 49-55. L'ouvrage de Wojtyska, Cardinal Hosius. Legate to the Council of Trent, Rome, Institute of ecclesiastical studies, 1967 permet de cerner les contacts avec le cardinal de Lorraine, mais ne s'étend pas au-delà de la période conciliaire.

83. Stanislas Hosius, Des sectes et hérésies de nostre temps, Paris, 1561, p. 51, 52, 70, 74.

84. BNF, ms. fr. 15967 , fo 141.

85. BNF, ms. fr. 15967, fo 149-50.

86. Blaise de Monluc, Commentaires, Paris, 1867, t. 3, p. 527.

87. Noailles, op. cit., t. 3, p. 34. Ce texte est dans BNF, ms. fr. 16936, fo 73.

88. «Catolici omnes leges habent in quibus est antiqua confoederatio cui haec recens contraria est. Si jurabit in utrumque jurabit contraria ». BNF, ms. fr. 3259 , fo 30 .

89. Karnkowski, Harangue publique de bienvenue au roy Henri de Valois, roy élu de Plogne avec la réponse du sieur de Pibrac, Paris, 1574. Ce texte a connu de nombreuses éditions. Dans son Des sectes et hérésies de notre temps, Hosius insiste déjà sur la fidélité permanente des rois de Pologne au catholicisme. Il signale que certains ont préféré refuser la couronne de l'hérétique Bohème plutôt que de compromettre leur salut et trahir le catholicisme. Le devoir d'un roi catholique est d'exterminer l'hérésie. Hosius, op. cit., p. 7,78 .

90. BNF, ms. fr. 5145, fo 185 .

91. BNF, ms. fr. 3259 , fo $30 \mathrm{v}^{\circ}$.

92. Antoine Maria Gratiani, La vie du cardinal Jean François Commendon, Paris, 1671, p. $465,476$.

93. Noailles, op. cit., t. 3, p. 564. «Si demostra ogni giorno piu la Maesta Sua cattolica et religiosa, et chiro segno tra gli altri ne diede uno di questi giorni, che essendo invitato pubblicamente dal palatino di Cracovia heretico a tener a battesimo un suo figliolo, gli ripose, che non poteva far questo, essendo lui di diversa religione della sua, tenedo pur a battesimo quella mattina medesima un figliolo d'un altro signor cattolico ».

94. Maciej Serwanski, « Henri de Valois et la diète de Pologne », L'Europe des diètes au XVII siècles, Paris, SEDES, 1996, p. 237.

95. BNF, ms. fr. 5145, fo 227. ms. fr. 3258, fo 74.

96. Jean Zamoscie, L'oraison du seigneur Jan de Zamoscie, Paris, 1574, p. 12 sq.

97. Karnkowski, op. cit., p. 24, 26.

98. Choisnin, op. cit., p 132.

99. Choisnin, op. cit., p. 204.

100. André Thevet, op. cit., t. 2, p. 880.

101. Jean-Marie Constant, «L'amitié : le moteur de la mobilisation politique dans la noblesse de la première moitié du XVIIe siècle », 205, Revue XVIIe, 1999, p. 593-608.

102. Je remercie particulièrement Arlette Jouanna pour cette remarque.

103. BNF, ms. fr. 5145, fo 126 ; ms. fr. 3258 , fo 35.

104. Ambrosius Calepinus, Dictionnarium latinum praeter adagia selectiro et gallicas, italicas,...Lyon, 1586. 
105. Jean Thierry, Dictionnaire français latin auquel les mots français avec les manières d'user... Paris, 1564, p. 131.

106. Le latin du XVI $\mathrm{X}^{\mathrm{e}}$ semble ignorer le mot confederatio. Voir René Hoven, Lexique de la prose latine de la Renaissance, Leiden, E. J. Brill, 1994.

107. Jehan Pasgrave, L'esclaircissement de la langue Françoise, Paris, 1530, fo 194. Au Moyen Âge, les très rares occurrences de confedéré ou confederacie semblent en revanche plus proches de notre sens d'association de compagnons ou de marchands. Mais pas d'emploi politique. Frédéric Godefroy, Dictionnaire de l'ancienne langue française, IX-XVe, Paris, 1891-1902, t. 2, p. 231.

108. Du Cange, Glossarium mediae et infimae latinatis, Niort, 1883, t. 2, p. 94. Pour Du Cange les synonymes de confederativus sont socius, amicus. Il ignore le verbe confédérer ou confédération.

109. Michel Rey «Communauté et individu : l'amitié comme lien social à la Renaissance », Revue d'histoire moderne et contemporaine, t. 38, 1991, p. 617-25. L'auteur montre que la conception de l'amitié sous le règne d'Henri III est marquée par le passage d'une conception traditionnelle et sociale de l'amitié, créatrice du bien public à une conception personnelle et donc factionnelle. Jusqu'alors valeur morale et sociale, l'amitié devient particulière, partisane et donc une passion répréhensible politiquement : ainsi les Mignons d'Henri III. Chez Montaigne enfin, l'amitié relève du choix individuel comme du reste la conscience religieuse. C'est ce qui explique que le chapitre « De l'amitié » des Essais est aussi celui dans lequel Montaigne plaide pour la tolérance. L'amitié vantée par Pibrac et les thuriféraires de la Pologne répond encore à la définition traditionnelle.

110. Karnkowski, op. cit., p. $31 v^{\mathrm{o}}, 33,39$.

111. Sur la fides, voir Jean Wirth, «La naissance du concept de croyance », Bibliothèque d'humanisme et renaissance, 44, 1983, p. 13-14.

112. Fonder la concorde sur la vertu, et non sur une démarche de nature juridique est une voie largement préconisée au XVI ${ }^{\mathrm{e}}$ siècle. Il faut changer les cœurs, non les lois. Quentin Skinner, Les fondements de la pensée politique moderne, Paris, Albin Michel, 2001, p. $81,101,128,321$. On renverra aussi à la très salutaire critique de Jean-Frédéric Schaub sur l'emploi galvaudé et mal délimité du « politique ». Le Portugal au temps du Comteduc d'Olivares, 1621-1640 : le conflit de juridictions comme exercice de la politique, Madrid, Casa de Valázquez, 2001. Voir les longues introduction et conclusion, qui dépassent de beaucoup le cadre portugais.

113. Marie-Dominique Chenu, La théologie au XIIe siècle, Paris, J. Vrin, 1957, p. 270. Sur la nature religieuse du serment, Paolo Prodi, Il sacramento del potere. Il giuramento politico nella storia costinuzionale dell'Occidente, Bologne, Il Mulino, 1992.

114. Ce lien entre la violence physique et la fidélité au roi permet de comprendre la cohérence de comportement des mignons. Le don de soi par le sacrifice est la signature de la fidélité. Nicolas Le Roux, La faveur du roi : mignons et courtisans au temps des derniers Valois (1547-1589), Seyssel, Champ Vallon, 2001.

115. Arlette Jouanna, Le devoir de révolte : la noblesse française et la gestation de l'État moderne (1559-1661), Paris, Fayard, 1989, p. 344-45. La Déclaration des causes qui ont meu ceux de la religion a reprendre les armes pour leur conservation en 1574, parue à Montauban en 1574 rappelle que les Polonais jouissent de la tolérance tout en montrant que les ambassadeurs polonais ont été trompés par Charles IX. Voir f $\mathrm{f}^{\mathrm{a}} \mathrm{a}, \mathrm{b} 1 \mathrm{v}^{\mathrm{o}}, \mathrm{b} 2 \mathrm{v}^{\mathrm{O}}$.

116. BNF, ms. fr. $3258, f^{\circ} 35 v^{\circ}$. 
117. Pierre et Solange Deyon se demandent ainsi si la minorité protestante n'a pas « orienté les institutions françaises dans un sens plus libéral ». Mais ils notent qu'Henri de Rohan a une sainte horreur de la diversité confessionnelle en Bohème et admire une Écosse exclusivement calviniste. Le libéralisme n'est donc pas d'essence religieuse mais seulement la revendication de privilèges par des minoritaires. Pierre et Solange Deyon, Henri de Rohan, Paris, Perrin, 1999, p. 39, 44.

118. Vindiciae contra tyrannos, Genève, Droz, 1979 (c'est l'édition de 1581), p. 115, 144, 147, 167, 170, 188.

119. Théodore de Bèze, Du droit des magistrats, éd. Robert Kingdon, Genève, Droz, 1970, p. 33-34. Je remercie Arlette Jouanna de m'avoir indiqué cette référence ainsi que la suivante.

120. Agrippa d'Aubigné, Les Tragiques, Paris, Gallimard, 1995, vers 713-19. Il évoque Henri III.

121. Ambroise Jobert, op. cit., p. 185.

122. Dominique Julia, Jacques Revel, Les Universités européennes du XVIe au XVIIIe siècle: histoire sociale des populations étudiantes, Paris, Éditions de l'École des hautes études en sciences sociàles, 1989, t. 2, p, 58.

123. Jean Philippe Genet a bien cerné le problème de l'histoire politique comparée lorsqu'il écrit : «La méfiance qu'inspire désormais l'État en général oppose les historiens des États issus des monarchies et ceux qui se sentent héritiers et porteurs des valeurs de la ville comme structure sociale du pouvoir ». "Genèse de l'État moderne. Les enjeux d'un programme de recherche », Actes de la recherche en sciences sociales, $\mathrm{n}^{\mathrm{O}} 118,1997, \mathrm{p}$. 18. Olivier Christin a conclu sa belle étude pionnière des paix de religion en Europe par cet exercice de science politique (La paix de religion : l'autonomisation de la raison politique au XVIe siècle, Paris, Seuil, 1997, p. 203-5) qui consiste à juger de l'aptitude de tel ou tel type de construction politique à assurer la tolérance religieuse. Sa conclusion est que « les structures étatiques de type fédéraliste, sans État central fort paraissent avoir mieux géré le défi de l'éclatement confessionnel ». Mais si l'on poursuit l'exercice, il y a des systèmes très décentralisés, type la monarchie composite et pactiste espagnole qui ont une politique d'intolérance religieuse. La ville peut être le cadre de la paix de religion. Mais aussi de la Michelade ou de la Saint Barthélemy. De même la monarchie anglaise est tout aussi intolérante vis-à-vis de sa minorité catholique que l'absolutisme français. Du reste, la minorité catholique attendait plus la tolérance du renforcement de l'autorité royale des Stuart que du parlement. Rappelons enfin qu'en France, la monarchie mixte du XVI ${ }^{\mathrm{e}}$ siècle, pourtant réclamée par certains protestants, n'a jamais pu assurer la paix de religion, d'où l'hyper-gallicanisme absolutiste des protestants français au XVII ${ }^{\mathrm{e}}$ bien établi par Elizabeth Labrousse. Au XVIII ${ }^{\mathrm{e}}$ siècle, la tolérance est soluble dans le despotisme éclairé comme en fait sinon en droit, dans l'absolutisme à la française. Rappelons enfin que l'empire Ottoman, modèle du despotisme pour tous les penseurs politiques de la période moderne est tolérant. Inutile de poursuivre l'exercice comparatiste pour en démontrer l'inanité. Ce ne sont pas les formes juridiques que revêt l'État qui conduisent à la tolérance ou à l'intolérance civiles, mais les forces et les pratiques sociales et religieuses en présence qui déterminent le degré de tolérance d'une société. La tolérance civile est certes une autonomie du politique, mais cette pacification provisoire est inscrite dans une stratégie religieuse de reconquête religieuse. La tolérance civile en France, c'est la reconquête catholique par d'autres moyens que la guerre. Toute une casuistique peut alors le démontrer. La cohabitation civile dans l'intolérance religieuse selon la belle et forte formule de Bernard Roussel. 